\title{
Gastric Acid Secretion and Diagnosis of Zollinger-Ellison Syndrome
}

\author{
M. R. LEWIN, B. H. STAGG, C. G. CLARK
}

British Medical fournal, 1973, 2, 139-141

\begin{abstract}
Summary
One hundred and fifty patients suspected of having ZollingerEllison syndrome were investigated. High plasma gastrin levels were found in 23 and in 16 a diagnosis of ZollingerEllison syndrome was confirmed. Measurement of the basal and maximal acid outputs showed that these simpler investigations have considerable value as screening tests for the selection of those patients in whom gastrin studies are indicated.
\end{abstract}

\section{Introduction}

The clinical syndrome described by Zollinger and Ellison (1955) consists of gastric hypersecretion and peptic ulceration (frequently multiple or in an unusual site such as the jejunum) associated with a non-beta islet cell tumour of the pancreas. Freisen et al. (1962) extracted a gastric secretagogue from such a tumour and Gregory et al. (1967) subsequently identified this secretagogue as gastrin.

The diagnosis of this syndrome is often made late, frequently after surgery for peptic ulcer has been performed. Measurement of gastric acid secretion is an accepted method of diagnosis in this condition, though confirmation by finding a high level of circulating gastrin is required. Unless routine measurement of serum gastrin is to be adopted in all patients with peptic ulcer, gastric secretion studies may be the only method generally available which will provide a means of early diagnosis. This investigation concerns an assessment of the various criteria of acid scretion thought to be useful in the diagnosis of the Zollinger-Ellison syndrome.

\section{Materials and Methods}

Samples of frozen plasma have been referred for gastrin assay from a variety of sources where the clinician suspected a diagnosis of the Zollinger-Ellison syndrome. From January 1970 to July 1972150 such samples were received. In return for this service we asked clinicians to co-operate by providing details of the clinical history, together with the results of gastric acid secretion studies. Clinical information was often incomplete and it seems clear that clinicians are reluctant in accepting acid measurements as an aid to the diagnosis of this condition.

The clinical details allowed the patients to be divided into three distinct groups according to the reason for suspecting the diagnosis of the syndrome. Group 1 consisted of 23 patients, who generally were in the younger age groups, with a short history of severe ulcer symptoms often complicated with

\footnotetext{
Surgical Unit, University College Hospital Medical School, London WC1E 6JI

M. R. LEWIN, PH.D., M.I.BIOL., Biochemist

B. H. STAGG, PH.D., M IIOL, Biochemist

C. G. CLARK, M.D., CH.M., Professor, and Director of Unit
}

perforation or bleeding. In addition some had multiple ulceration and/or evidence of gastric hypersecretion, usually a high basal acid. In group 2 there were 39 older patients with suspected or proved recurrent ulceration after one or more operations for peptic ulceration. Group 3 consisted of 13 patients with a variety of symptoms, the only common factors being either evidence of malabsorption or a diagnosis of another endocrinopathy such as hyperparathyroidism or Cushing's syndrome.

Acid secretion studies from 100 patients treated in the surgical unit for chronic duodenal ulcer and 25 treated for chronic gastric ulcer were also examined for comparison.

The information on acid secretion has been expressed in respect of a one-hour basal acid output (B.A.O.) and a maximal acid output (M.A.O.) after either pentagastrin or histamine stimulation. These measurements were used to calculate a B.A.O./M.A.O. ratio. In addition the ratio of basal acid concentration to maximal acid concentration (B.A.C./M.A.C.) was calculated.

Plasma gastrin concentrations were measured by radioimmunoassay as described by Wyllie et al. (1972).

\section{Results}

The criteria of acid secretion recommended as useful in the diagnosis of the Zollinger-Ellison syndrome are given in table I. These recommendations are often based on limited observations, in table II a comparison is made of the frequency with which each criterion occurs in a population

TABLE I-Criteria of Acid Secretion in Diagnosis of Zollinger-Ellison Syndrome

\begin{tabular}{l|c|c}
\hline \multicolumn{1}{c|}{ Source } & $\begin{array}{c}\text { No. of } \\
\text { Observations }\end{array}$ & \multicolumn{1}{c}{ Criteria } \\
\hline Zollinger and Ellison, 1955 & 2 & $\begin{array}{l}\text { Nocturnal 12-hr secretion } \\
>1,000 \mathrm{ml} \text { or }>100 \mathrm{mBq}\end{array}$ \\
Aoyagi and Summerskill, 1966 & 134 & $\begin{array}{l}\text { Hourly B.A.O. }>15 \mathrm{mEq} \\
\text { (postop. stomach, }>5 \mathrm{mEq} \text { ) }\end{array}$ \\
$\begin{array}{l}\text { Marks et al., 1961 } \\
\text { Ruppert et al., 1967 }\end{array}$ & 1 & $\begin{array}{l}\text { B.A.O./M.A.O. ratio >0.6 } \\
\text { B.A.C./M.A.C. ratio >0.6 }\end{array}$ \\
\hline
\end{tabular}

TABLE II-Acid Secretory Criteria in 100 Patients with Duodenal Ulcer and 25 with Gastric Ulcer Referred for Surgery

\begin{tabular}{l|c|c|c}
\hline \multicolumn{1}{c|}{ Criterion } & $\begin{array}{c}\text { Duodenal Ulcer } \\
(\mathbf{n}=100)\end{array}$ & $\begin{array}{c}\text { Gastric Ulcer } \\
(\mathbf{n}=25)\end{array}$ & Total \\
\hline $\begin{array}{c}\text { B.A.O. }>15 \mathrm{mEq} / \mathrm{hr} \\
\text { B.A.O./M.A.O. }>0.6\end{array}$ & $\begin{array}{c}\mathbf{2}(2 \%) \\
10(1 \%)\end{array}$ & $\begin{array}{c}1(4 \%) \\
1(4 \%)\end{array}$ & $\begin{array}{r}3(2.4 \%) \\
2(1.6 \%) \\
10(8.0 \%)\end{array}$ \\
\hline
\end{tabular}

suffering from peptic ulceration without evidence of hypergastrinaemia. Of the 100 patients with duodenal ulcer, $2 \%$ had a basal acid secretion of greater than $15 \mathrm{mEq} / \mathrm{hr}, 1 \%$ had a B.A.O./M.A.O. ratio greater than 0.6 , and $10 \%$ had a B.A.C./ M.A.C. ratio greater than 0.6 . In 25 patients with chronic gastric ulcer an abnormally high basal acid was found in one patient, and an abnormal B.A.O./M.A.O. ratio occurred in another. Both these patients, however, suffered from combined gastric and duodenal ulceration. These results indicate that the 
criteria of acid secretion proposed for the diagnosis of the Zollinger-Ellinson syndrome will occasionally provide false positive results, this error being greatest with the B.A.C./ M.A.C. ratio.

The normal level of fasting plasma gastrin in this laboratory ranges from 50 to $170 \mathrm{pg} / \mathrm{ml}$ (Wyllie et al., 1972). A diagnosis of hypergastrinaemia consistent with a diagnosis of the syndrome was made in 23 subjects and in 16 the diagnosis was confirmed by operation and histological studies. The levels of fasting plasma gastrin in these 23 patients ranged from 900 to $9,500 \mathrm{pg} / \mathrm{ml}$. All of the group 3 patients were found to have normal levels of plasma gastrin.

The results of the B.A.O. and M.A.O. for groups 1 and 2 are given in fig. 1, which shows each group subdivided according to whether the fasting plasma gastrin level was normal or raised. There was a significant difference in the B.A.O. between the ulcer subjects and those with hypergastrinaemia in both groups 1 and $2(P<0.01)$, but there was no difference in the M.A.O. $(P>0.20)$. Examination of the individual results in group 1 showed that five of the 15 patients (30\%) with

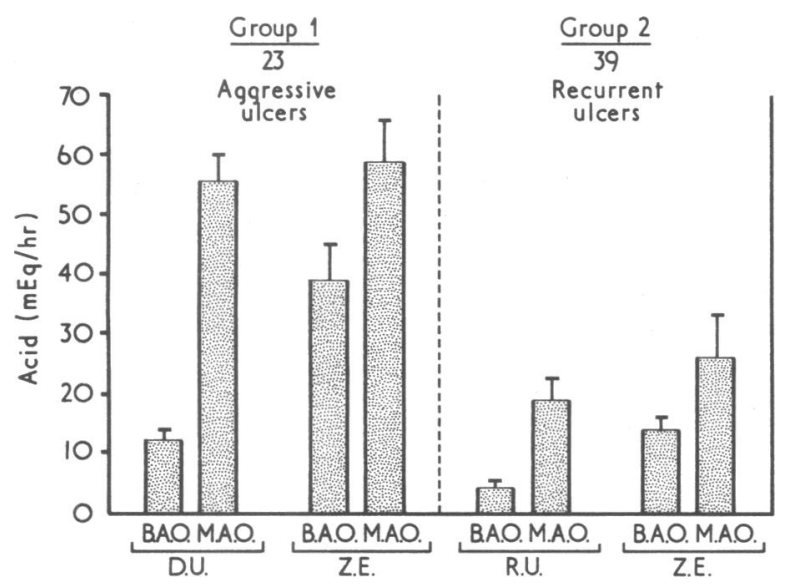

FIG. 1-Means \pm S.E. of mean of basal and maximal acid outputs in group 1 and 2 patients. These groups have been further subdivided into those with and without a diagnosis of Zollinger-Ellison (Z.E.) syndrome.

duodenal ulcer had an abnormally high B.A.O. (false positive) while two of the eight patients with hypergastrinaemia $(25 \%)$ showed a false negative result. Similarly, in the group 2 patients there were five false positives in 19 patients $(26 \%)$ with recurrent ulcer and normal gastrin levels, and in nine hypergastrinaemic patients there was one $(11 \%)$ who did not have a high B.A.O. (false negative).

The results of the B.A.O./M.A.O. ratio are shown in a similar manner in fig. 2. In group 1 none of the patients with duodenal ulcer had an abnormal ratio, but of the eight patients with hypergastrinaemia there were five false negative results (62\%). Similarly, in 15 of the group 2 patients with recurrent ulcer there were no false positives, but there were five false negative results in nine of the patients with hypergastrinaemia (55\%).

TABLE III-Twelvo-hour Secretion Studies in Eight Patients with Hypergastrinaemia and Previous Surgary

\begin{tabular}{c|c|c}
\hline Case No. & 12-hour Volume (m) & Acid (mEq) \\
\hline 1 & 200 & 120 \\
2 & 1,200 & 302 \\
3 & 3,350 & 50 \\
4 & 1,220 & 60 \\
5 & 1,114 & 21 \\
6 & 268 & 124 \\
7 & 1,150 & -
\end{tabular}

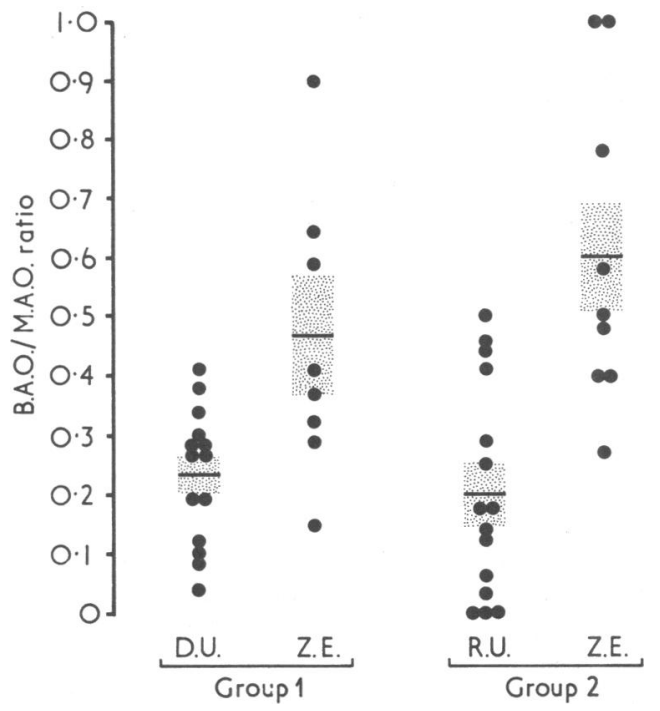

FIG. 2-Individual results with means \pm S.E. of mean for B.A.O./M.A.O ratio in group 1 and 2 patients. These groups have been further subdivided into those with and without a diagnosis of Zollinger-Ellison (Z.E.) syndrome.

The limited details available on concentration ratios were inadequate to provide meaningful information. The available data on 12-hour overnight secretion was sufficient in only eight patients with hypergastrinaemia, all of whom had undergone previous surgery. These results are detailed in table III. Two of the patients had volumes of less than $1,000 \mathrm{ml}$ and both had less than $100 \mathrm{mEq}$ of acid. The remaining six patients all had 12-hour volumes in excess of $1,000 \mathrm{ml}$, but of these there were only three with an abnormally high acid secretion in excess of $100 \mathrm{mEq}$.

\section{Discussion}

Despite a growing awareness of the Zollinger-Ellison syndrome, these results suggest that referrals for diagnosis are somewhat haphazard. The subdivision of the patients into clinical groups was sufficiently accurate to compare the case histories within groups. There was no real difference in the clinical history of the patients in group 1 when comparing those with and without hypergastrinaemia. Frequently the diagnosis of the syndrome was first considered when the patient developed a recurrent ulcer after surgery, usually for duodenal ulcer. It was most often considered, and rightly so, in patients who had undergone multiple operations for recurrent ulcer. Yet even here there was little difference in patients from group 2, comparing those with and without hypergastrinaemia. Clearly the history is inadequate to suggest the diagnosis in the highly selected group of patients referred to us. Carried to its logical conclusion this would suggest that the only way to diagnose this disease is to measure the plasma gastrin in all patients with peptic ulcer. This should not prove an impossible task for the few centres with facilities for gastrin radioimmunoassay, but as yet the organization is lacking.

Measurement of acid scretion is an accepted method of providing strong circumstantial evidence in favour of a diagnosis of the Zollinger-Ellison syndrome. It was surprising, therefore, that in only half of the referrals were there any details of gastric acid secretion provided. This appeared to be because such tests were not performed, rather than failure to communicate. It may be that clinicians place little value on acid secretion measurement either in peptic ulcer or in recurrence after gastric surgery. It was more surprising, however, to find such negligence in a group of patients where a diagnosis of the syndrome was being considered. 
The criteria of acid secretion said to be indicative of the syndrome have been examined in relation to the frequency with which such abnormalities occur in a population of patients with peptic ulcer referred for surgery. The frequency of apparently false positive results in patients with normal levels of plasma gastrin was low in respect of a B.A.O. being greater than $15 \mathrm{mEq} / \mathrm{hr}(2.4 \%)$ and a B.A.O./M.A.O. ratio greater than $0.6(2 \%)$. The frequency of false positives, however, was considerably greater with the B.A.C./M.A.C. ratio more than $0.6(10 \%)$. Similar results were found by Kaye et al. (1970) who examined 90 patients with duodenal ulcer. They found a higher proportion of patients $(10 \%)$ who had a basal acid output greater than $15 \mathrm{mEq} / \mathrm{hr}$, but their results for the B.A.O./M.A.O. ratio and B.A.C./M.A.C. ratio were almost identical with ours, being $2 \%$ and $12 \%$ respectively. These false positives need not detract from the value of measuring both B.A.O. and M.A.O., for this would clearly help to reduce the problem of screening if only patients with such abnormalities were referred for plasma gastrin assay. However, the frequency of false negative results in patients with hypergastrinaemia needs to be considered.

Studies of acid secretion in patients with an established diagnosis of the Zollinger-Ellison syndrome are few. In a review of 134 cases taken from the literature Aoyagi and Summerskill (1966) concluded that a B.A.O. of greater than 15 $\mathrm{mEq} / \mathrm{hr}$ was highly suggestive of the syndrome in the unoperated patient, and a value greater than $5 \mathrm{mEq} / \mathrm{hr}$ in patients with previous gastric surgery. Nevertheless, from their data it can be seen that 13 of their 30 patients who had not undergone previous surgery had a basal acid secretion within their normal limits for duodenal ulcer; but 10 of the 14 patients previously submitted to surgery had a B.A.O. greater than 5 $\mathrm{mEq} / \mathrm{hr}$. Winship and Ellison (1967) examined the basal acid output in four patients with the syndrome and found it to be abnormally high in three. On subsequent testing, however, one of these three patients had a normal B.A.O. In an analysis of 25 cases Way et al. (1968) reported details of basal acid secretion in 13 patients, but in only seven was it abnormally high. Isenberg et al. (1971), in a study on six patients, found a high B.A.O. in all, with a B.A.C. greater than $100 \mathrm{mEq} / \mathrm{l}$. in four of them. From our own referred patients, a raised level of B.A.O. was certainly the one criterion most familiar to clinicians. It probably accounted for the high proportion of false negative results, since the frequency with which it occurred was much greater than the comparatively low incidence found in the control population.

Another well recognized criterion in the diagnosis of the Zollinger-Ellison syndrome is a B.A.O./M.A.O. ratio greater than 0.6, as proposed by Marks et al. (1961). In our own control ulcer population this criterion had a low frequency similar to that reported by Kaye et al. (1970). In five proved cases of the syndrome Ruppert et al. (1967) found two patients with a false negative B.A.O./M.A.O. ratio while Winship and Ellison (1967) found the ratio to be falsely negative in one of the four cases described by them. Calculation of the B.A.O./M.A.O. ratio from the data for the seven patients reported on by Way et al. (1968) showed the ratio to be greater than 0.6 in all of them. Despite the high incidence of false positive results with basal secretion in our group 1 and group 2 patients with normal gastrin levels, there were no false positive results using the criterion of B.A.O./M.A.O. ratio. However, like Aoyagi and Summerskill (1966), we found that this criteria used alone in unoperated patients would have failed to indicate the diagnosis in more than half.
It is not surprising that the B.A.O. or the B.A.O./M.A.O. ratio should sometimes fail to reflect the diagnosis, since Thompson et al. (1972) showed that basal serum gastrin concentration can vary widely in some patients. Winship and Ellison (1967) provided indirect evidence in support of this view by showing variability of acid secretion measurements in some of their patients.

A B.A.C./M.A.C. ratio of greater than 0.6 , as described by Ruppert et al. (1967), was abnormally high in all of their five patients with islet cell tumours. In the four patients examined by Winship and Ellison (1967) the B.A.C./M.A.C. ratio was abnormally high in three of them, though one of these three patients did give false negative ratio on subsequent testing. The high incidence of false positive results in our own control ulcer group and that found by Kaye et al. (1970) seems to detract greatly from the value of this criterion.

There have been many references to patients with the syndrome with overnight secretions of more than $1,000 \mathrm{ml}$ or $100 \mathrm{mEq}$ of acid since the first suggestion by Zollinger and Ellison (1955). Four out of five patients with the syndrome studied by Ruppert et al. satisfied this criterion; but only one of three proved cases described by Winship and Ellison (1967) was positive, and then only on the second test of overnight secretion. In our patients this criterion seems to have been considered only in those referred after recurrent ulceration. In patients with hypergastrinaemia a secretion volume of greater than $1,000 \mathrm{ml}$ was found in six out of eight patients, and three of these had outputs of greater than $100 \mathrm{mEq}$ of acid. This criterion may thus prove to be of great value in the diagnosis of the syndrome, but more information is needed.

Our total data showed that acid secretion studies in patients with suspected Zollinger-Ellison syndrome were performed in a haphazard wav and did not allow for a full assessment of the value of such studies in screening. Although only the B.A.O. and the overnight secretion appeared to have real diagnostic value, the B.A.O./M.A.O. ratio was also of some help. Despite false negative results in each single criterion of acid secretion, it is possible that multiple criteria could prove to be of greater value in diagnosis, though this was difficult to judge since information both from this study and from the literature was inadequate. The results of an overnight secretion and a pentagastrin test in all patients suspected of hypergastrinaemia would thus help to provide information which at present is lacking.

\section{References}

Aoyagi, T., and Summerskill, W. H. J. (1966). Archives of Internal Medicine, $117,667$.

Freisen, S. R., Tracy, H. J., and Gregory, R. A. (1962). Annals of Surgery,

Gregory, R. A., Grossman, M. I., Tracy, H. J., and Bentley, P. H. (1967). Lancet, 2, 543 .

Isenberg, J., Csendes, A., and Walsh, J. H. (1971). Gastroenterology, 61, 655. Kaye, M. D., Rhodes, J., and Beck, P. (1970). Gastroenterology, 58, 476.

Marks, I. N., Selzer, G., Louw, J. H., and Bank, S. (1961). Gastroenterology, 41, 77 .

Ruppert, R. D., Greenberger, N. J., Beman, F. M., and McCullough, F. M (1967). Annals of Internal Medicine, 67, 808.

Thompson, J. C., Reeder, D. D., and Bunchman, H. H. (1972). American fournal of Surgery, 124, 250 .

Way, L., Goldman, L., and Dunphy, J. E. (1968). American fournal of Surgery, 116, 293

Winship, D. H., and Ellison, E. H. (1967). Lancet, 1, 1128.

Wyllie, J. H., Boulos, P. B., Lewin, M. R., Stagg, B. H., and Clark, C. G. (1972). Gut, 13, 887 .

Zollinger, R. M., and Ellison, E. H. (1955). Annals of Surgery, 142, 709. 